\title{
Critical Literacy: Beyond Reading and Writing in the Bahamian Tertiary Classroom
}

\author{
Marie Sairsingh \\ University of The Bahamas ${ }^{1}$
}

\section{Abstract}

Critical literacy can be defined as a cluster of specialized skills and competencies that facilitate an intensely engaged way of interpreting our world through careful textual and discursive analyses. It involves understanding the processes of learning to read and write as the precursor to a heightened awareness of one's location within specific power relations, as well as its importance to ensuring a sustainable democracy. Ultimately, critical literacy is an indispensable component of the broader literacy mandate at the University of The Bahamas, as it can propel students toward greater participation in national discourse, and ultimately, toward meaningful social transformation. While this paper presents anecdotal rather than analytic evidence of students' growth toward increased critical intelligence, it provides significant insight into the processes of their intellectual growth.

\section{Introduction}

The skills of reading and writing constitute the core mass of all educational pursuits. Basic literacy, defined as the ability to read and write, is indispensable to attaining broad national goals such as eliminating poverty, decreasing infant mortality rates, eradicating racial and gender inequity, righting socioeconomic imbalance, and achieving sustainable development. As a developing country with the foregoing social and economic challenges and goals, achieving literacy is crucial to The Bahamas' continued development. Yet while the importance of basic literacy is acknowledged, equally important to meeting these challenges is attaining critical literacy, understanding the processes of learning to read and write as the precursor to a heightened awareness of one's location within specific power relations; understanding its importance to maintaining a viable democracy (Anderson \& Irvine, 1993, p. 82). Critical literacy is, thus, the lens through which we examine texts in various forms and modalities, and challenge assumptions and ideas about our society and our world. Ultimately, it involves recognizing the power not only to read and critically analyze ideas, but, where necessary, to present alternative perspectives on issues of national importance; thus, critical literacy can propel students and citizens, more broadly, toward greater participation in national discourse, and ultimately, toward meaningful social transformation.

${ }^{1}$ Marie Sairsingh, English Studies, University of The Bahamas.

E-mail: marie.sairsingh@ub.edu.bs

Acknowledgements: A version of this paper was presented at the English Studies Summer Workshop, May 15-17, 2017.

APA reference: Sairsingh, M. (2017). Critical literacy: Beyond reading and writing in the Bahamian tertiary classroom. International Journal of Bahamian Studies, 23, 31-39. https://doi.org/10.15362/ijbs.v23i0.291

(C) M. Sairsingh, 2017. Journal compilation (c) International Journal of Bahamian Studies, 2017 


\section{Paulo Freire and Critical Pedagogy}

As a pedagogical method, critical literacy is attributed to Brazilian education theorist, Paulo Freire, whose radical and liberatory approach to teaching Brazilian rural peasants in the mid-1960s following the military overthrow of civilian rule in Brazil went against the grain of the hegemonic education system, in which education was delivered in an unquestioned and non-participatory fashion; where the teacher was the repository of all knowledge and the students were the passive recipients upon whom this knowledge was bestowed. In such a system, students had only the illusion of being educated, and being able to understand and take control of their circumstances. Freire contended that when the critical faculties of students are nurtured through dialogue on issues important to their lives, students develop critical consciousness, an in-depth understanding of the world (2009, pp. 101-110) and acquire the rhetorical skills and the discourse capital to challenge and transform it.

In the Bahamian context, an important goal of the University of The Bahamas is to "foster national, regional, and international development" and to "meet the educational aspirations of its students and nurture their creativity" (University of The Bahamas, 2017b), while also promoting the "values of learning, leadership and service" (University of The Bahamas, 2017a). These goals are achieved through empowering students to become questioning and analytical citizens within the 21st century globalized world by developing a keen critical consciousness. Critical literacy, I argue, is an indispensable component of the broader literacy mandate at the University of The Bahamas.

English 300: Advanced Writing (ENGW300) and courses in disciplines other than English Studies that have similar foci form a core element in attaining the foregoing goals of the institution. By way of illustrating how
ENGW300 can deepen students' awareness and spawn the growth of critical literacy, I offer reflections on my experience teaching ENGW300 in Fall 2016. While these reflections present anecdotal rather than analytic evidence of students' critical acumen, they provide some insight into the processes of their intellectual growth.

\section{Incorporating Critical Literacy}

During the English Studies Summer Workshop held at the University of The Bahamas, May 15-17, 2017 under the theme, "Forging Ahead", one of the sessions highlighted the work of the University of The Bahamas' Task Force charged with examining the general education requirements of bachelor degree programs to determine what, if any, changes are warranted regarding these requirements. The work of the Task Force has clear implications for ENGW300, which currently fulfills the upper-level literacy requirement of all bachelor degree programs in the University. Some academic constituents of the University have questioned the efficacy of retaining ENGW300 as a required course, arguing that such a requirement is inconsistent with the practice of many North American universities. While it is true that many Canadian and United States universities do not require students English composition courses beyond first year, it could be that these institutions' policies and practices are based on composition studies that, as Bain (2005) asserts, "have limited their scope to investigating the teaching of English as a first language" (p. 11). In the Bahamian context, given the undeniable challenge posed to some of our English Creole speakers with respect to attaining solid proficiency in Standard English, it might be desirable to have a thirdtier course that addresses some of the deficits observed in students' writing.

Oenbring, Jaquette, Kozikowski and Higgins (2016) pointed out, 
Ongoing concern among both $\mathrm{COB}$ faculty and the broader Bahamian community regarding COB students' and graduates' continuing difficulties with writing standard English eventually led to the development of a third English composition course designed to be taken in the third year, specifically English 300/301" (p. 44).

\section{Increasing Analytical Acumen}

The focus of the original ENG301 Advanced Writing Skills course was on teaching "skills required for reading, writing and thinking critically at an advanced level" and on "writing effective arguments within and across disciplines." The course foregrounded research, organizational strategies, academic writing principles, grammar and mechanics. A driving force behind its subsequent revision in 2007, when its designation changed to ENG300 Advanced Writing: Bahamian Culture and Society, was to augment the existing course so that it would fill recognized gaps in students' knowledge in the areas of civics (theoretical and practical aspects of citizenship), and various aspects of Bahamian life. Conceived along similar lines as University of the West Indies' Caribbean Civilization course FOUN1101, which maps specific content areas "to ensure that students understand the contemporary Caribbean as an autonomous area of study (through its interdisciplinary regional lens) on par with other area studies within a global context," ENG300 was revised with a cultural-studies focus. Ian Strachan, one of the architects of the re-conceptualized course acknowledges the critical importance of including content that explores and reinforces knowledge in such areas as Bahamian history, nation and identity, international relations, tourism, governance, gender and sexuality, race and class, culture, the environment, the economy, and religion. Strachan asserted that redesigning the course was premised on the need to provide a course that thematized Bahamian studies and "gave students an opportunity to engage analysis of discourse around the various dynamics of nationhood" (I. G. Strachan, personal communication, September 24, 2017).

Beyond providing students further opportunity to master written standard English language conventions, ENG300 and later, ENGW300 sought and still seeks to produce students who are proficient in specific rhetorical skills and in their knowledge of Bahamian cultural and society, this latter involving the examination and understanding of the Bahamian ethos. As articulated on the course outline, ENGW300's objectives require students to "analyze discourse across the disciplines addressing a variety of issues of national importance in The Bahamas," and to "conduct research into the socio-cultural, political, economic, and environmental aspects of Bahamian life," culminating in "the production of original, informed and analytical responses to readings, including research-based responses."

This intellectual exercise in critical thinking takes as its objects of study diverse sociocultural and discursive forms, and seeks to engender in students a greater sense of participation in national discourse on issues of importance to the nation. The processes of the course also call upon students to examine and evaluate, among other things, whose knowledge and whose perspectives are privileged in texts, and whose are elided, understanding that, as Trinidadian writer Dionne Brand (1998) reminds us, no language is neutral but that all language comes loaded with its own ideological baggage and prescribed interpretations. Developing skills for critical literacy enables students to navigate through and beyond text to construct meaningful, relevant, and sustainable knowledge.

The course outline reflects ten generative 
themes that shape the Bahamian way of life, and students are required to engage with two or more of these themes through the course texts in ways that ultimately engage and reflect critical literacy. This focus on critical literacy is intended to propel students toward full discursive participation by examining texts in various forms and modalities and challenging assumptions and ideas about our society and our world. Ultimately, it is about recognizing the power of the active reader to change the script and thus, the message, by presenting alternative perspectives that have either been underrepresented, or occluded, all while paying close attention to the conventions of English language to produce coherence, lucid, and intelligible responses.

\section{Reading Cultural Iconography}

Upon reflection, my ENGW300 course taught in Fall 2016, revealed that students' engagement with course texts and with the articulated course objectives, aligned with those expressed in the course documents, yielded very favorable results - both at the level of sophisticated thought processes, and improved writing competence. I present here a few of the core texts, mapping the ways students were challenged to question takenfor-granted truths packaged and disseminated in canonical texts and in cultural iconography. The generative theme for the class was "Identity in the Bahamian/Caribbean Context." The readings selected for the course were varied both in terms of their complexity and their thematics. Consistent with its objectives, the course required students to interact with challenging material and to interrogate the constitutive elements of Bahamian national and Caribbean regional identity. Descriptors such as gender, age, sexual orientation, race, ethnicity, and religion, were among the items in the identity matrix under consideration. Hence, students' exposure to texts that variously discussed these elements and argued from both inclusionist and exclusionist standpoints was intended to allow them to think deeply about each topic within a comprehensive analytic frame.

The first reading, "Roots or Routes: Migrations of Identity in The Bahamas" (2007) by Nicolette Bethel discusses the problematics of using identity formation theory developed/derived from elsewhere to read Bahamian culture. One such theory, the work of Peirce Lewis, asserts that "tangible objects" like iconography can be read as "cultural autobiography." Bethel comments in her text on the statues in Parliament and Rawson Squares respectively. She writes:

In Parliament Square to the south, surrounded by the seats of government, sits a statue of Queen Victoria. She is carved out of whitewashed stone, larger than life, stern, raised on a pedestal, which requires the craning of necks to admire her. Hers is a monument erected during the early years of the twentieth century in memory of the queen who created a global empire and freed the slaves. To the north, in Rawson Square, blending with the landscaping designed to welcome cruise ship passengers to the center of town, is the smiling torso of Sir Milo Butler, first Governor General of the Commonwealth of the Bahama. Cast in green tinged bronze, he is placed at such a level that one can look him in the face. Not only is his torso shorter in stature than the Queen's, but it also has a considerably shorter pedigree, and its associations are considerably less lofty (2007, p. 77)

"Reading" these artifacts, Bethel asserts, one might assume that Bahamian national identity is a "poor thing" and is still "tied to its imperial past," given the preeminence of colonial iconography (2007, p. 77).

After reading this selection, I asked students 
to grapple with the foregoing assumptions, and to construct an argument that refutes those assumptions. I received some startlingly insightful responses. One student quickly stated in a rather querulous manner, "What about the sculptures at Clifton Pier?" I pressed him for a coherent elaboration of the idea he was proffering. He referred latterly to the powerful and evocative wooden sculptures carved out of Casuarina trees stumps by Bahamian artist Antonius Roberts at Clifton Cay Heritage Park, a site known as Sacred Space. Reading this site as a monument to the resistance and resilience of the enslaved population, he ventured that while images such as Queen Victoria and Christopher Columbus and Woodes Rogers are important markers within the hegemonic historical narrative, alternative "texts" also tell the national story and foreground those voices usually elided in official documents or artifacts. In this way, he demonstrated critical awareness of the ways in which counterdiscourse impels a re-evaluation of received knowledge. Some of the other students were not initially convinced that Sacred Space sculptures and those of Christopher Columbus and Queen Victoria belonged in the same category. They challenged his assertion, stating that Roberts' rendition, a relatively new project, was not entrenched within the national consciousness as were the other statues that were erected many decades earlier. While his initial comment was a kneejerk or intuitive response that needed to be elaborated, he achieved this by writing a wellstructured argument with relevant, compelling support.

\section{Analyzing Hegemonic Perspectives}

Another example of students' critical engagement was observed in their response to Howard Johnson's article, "National Identity and Bahamian Culture" (2000) in which Johnson quotes the late British/Canadian historian, Michael Craton, who wrote $A$
History of The Bahamas, published in 1962. In Johnson's quoted excerpt, Craton, writing of the diverse ethnicities of the Africans who came to The Bahamas on board the slave ships states:

Practically their only common denominator was ignorance and primitive barbarism. For good or bad, the institution of slavery gave these Africans their first unity. Very quickly their tribal identities broke down; their babble of tongues before the unity of a single European language; their customs before the unity of a single law; their religion before the attractions or organized coercion of Christianity" (cited in Johnson, 2000, p. 16).

After reading the quotation, I invited students to offer verbal responses to the text. There was an initial silence. I then asked students whether they detected any bias, any veiled ideological elements within the language of the text. In the discussion that ensued, some students stated that the Africans were described in ways that denigrated them. For example, they honed-in on such terms as "ignorance," "primitive barbarism," and "babble." One female student said that history texts are supposed to be objective but that this account didn't seem objective. The presumed objective lens of the AngloCanadian historian was called into question. As participation grew, other students detected language that seemed to inferiorize the African, his language, and his culture, while seemingly valorizing European language and cultural practices. However, while the indictment and dehumanization of the African subject, clearly, did not go undetected, students nonetheless did not necessarily view Craton, the historian, as a villain. Rather, they demonstrated an understanding of the dynamics of white hegemony within academic texts. One student stated, "his perspective is determined by where he was trained-the 
position from which he sees things." Craton's later collaboration with Bahamian historian Gail Saunders has yielded a two-volume history of the Bahamian people $(1992,1998)$. One student asserted that he would seek out those texts, as he was curious as to the perspectives from which they were written; he stated that though he had had a cursory look at the first of the two-volume work in a history course at University of The Bahamas, he was motivated to examined both texts more thoroughly to determine whether, in his view, they represented a balanced, objective account. In sum, as expressed in their various articulations, the class learned that even acclaimed publications attributed to renowned authors are not necessarily free of bias and can sometimes be sprinkled with subjective cadence.

\section{Challenging Heteronormativity}

Perhaps the most controversial text included in the semester's readings was an article by M. Jacqui Alexander, Trinidadian professor emeritus, who taught in University of Toronto's Women and Gender Studies Institute. Her essay is entitled, "Not Just (any) Body can be a Citizen: The Politics of Law, Sexuality and Post-coloniality in Trinidad and Tobago and The Bahamas." Alexander begins her article thus:

I am an outlaw in my country of birth: a national but not a citizen ... I was taught to believe "Massa Day Done," that there would be an imminent end to foreign domination. Subsequent governments have not only eclipsed these promises, they have revised the very terms of citizenship to exclude me. No longer equal, I can be brought up on charges of 'serious indecency' under the Sexual Offences Act of 1986, and if convicted, serve a prison term of five years. In The Bahamas, I can be found guilty of the crime of lesbianism and imprisoned for twenty years (2013, p. 91).
Alexander's scholarship addresses a variety of issues including the importance of teaching for social justice, the need for critical interdisciplinarity, and the contested centrality of (hetero)sexuality to the project of nationbuilding. The latter focus is exemplified in the article we read as part of the course syllabus.

Although the sexual offences acts of Trinidad and Tobago and The Bahamas to which Alexander refers have both since been repealed, I asked students to examine Alexander's argument within the frame of the exclusionary rhetoric of nation-state discourse. Given the wide subscription to Christian or religious doctrine that informs students' attitudes about non-normative sexuality, some members of my class had difficulty examining Alexander's critique of nationalism's heteronormative imperative outside of the precincts of their religious conviction. As an academic exercise, as one of my students told me, she could discuss the article and see some merit in Alexander's argument, but in the context of her own Christian conviction, she felt that Alexander's stance was just simply immoral, just "plain wrong." I coupled this article with a shorter piece by Greek-Bahamian writer, Helen Klonaris, in which she discusses her experience of ostracism as a member of the LGBT community by churches and religious organizations (Klonaris, 2008).

I determined that Alexander's counterdiscourse to heteronormativity, and her views on sexual autonomy and identity, and Klonaris' criticism of the religious hypocrisy among the clergy across Christian denominations posed a serious challenge for students. These ideas, baffling to many, temporarily halted intellectual exploration, despite efforts to engage students further, possibly out of fear that engaging a serious discussion about these texts would be contrary to doctrinal beliefs and biblical tenets and 
make them even more uncomfortable. While I respected this, I encouraged students to be mindful of, and indeed, to examine the paradoxical spaces that we so often inhabit, and explore how we might best deal with the cognitive dissonance that often ensues. I also reminded them of rhetorical sensitivity and of the need for civility in acknowledging the ideas of others even when these ideas seemed incongruent with their own value systems. In designated groupings, student analyzed and offered oral presentations on the two pieces - one, a dense, academic essay, the other, an intensely personal response, mapping the rhetorical strategies that each writer employed and examining the different arsenals of appeal used in constructing the respective arguments. They also examined and commented on the different levels and characteristics of language, based on the intended audiences of the respective pieces. The assignment foregrounded the course's focus on honing skills of rhetorical analysis and on presentations that utilized graphic aids and oral strategies. Many students displayed far less discomposure and awkwardness when offering comments within a group setting, rather than individually.

\section{Residual Racism: Fact or Fiction?}

The last example is drawn from Patricia Glinton-Meicholas' essay 'Uncovering the Bahamian Self" in which she draws an analogy between the former apartheid system of South Africa and what she refers to as The Bahamas' "most perfect model of apartheid." She writes:

We have been taught to believe that The Bahamas has no serious problems relating to race. That is probably because we support the most perfect example of Apartheid the world has ever known. If South Africa had adopted the Bahamian model, it would not now be in such turmoil. That model is simple. Majority rule, minority economic power. In short, let 'em sit in the halls of Parliament, keep the land and the money, while fostering this misconception that the purse strings are loosening (Glinton-Meicholas, 2000, p. 106).

For this assignment, students were asked to explain the analogy that Glinton-Meicholas used, and to assess its validity.

There was a considerable range of responses: some students found the analogy offensive and explained that it undercut the important political achievement of majority rule, and independence, since it flagrantly asserted the continued existence of white supremacy in the Bahamian context. To some, GlintonMeicholas' comparison between The Bahamas and South Africa seemed either to disregard or trivialize the political overthrow of the Bay Street Boys that ushered in black political leadership. One student suggested that, based on his research on the apartheid system, the analogy that Glinton-Meicholas sought to draw between such a system and The Bahamas was inherently flawed. He argued that that the South African model was characterized by disenfranchisement at multiple levels, and that black South Africans were shunted to townships and in segregated barracks-like dwellings, while black Bahamians were free to live anywhere they pleased. Others contradicted the latter student's assertion that blacks were free to live "anywhere they pleased," citing the many gated communities to which many of them do not have access, either due to the colour of their skin or their lack of financial resources. Others, still, acknowledged the ongoing racial tension and racial divide that still exists in The Bahamas, but critiqued the writer's use of overstatement and hyperbole to make her point. As a culminating exercise rising from this discussion, students were asked to write a paragraph agreeing with or refuting the notion that racism is still alive and evident in The Bahamas. They were reminded to adhere to 
the conventions of structuring an argument, and marshalling the requisite support for their position.

These four examples show students interacting with texts on several different topics and overlapping issues: defining cultural identity, interrogating history, the contours of non-normative sexuality and heteronormativity, and covert racism in Bahamian society. While not a formal study with measurable outcomes, the anecdotes map students' intellectual explorations during the 14 week semester, and provide some indication of their expanded sense of critical engagement. Several students indicated in their reflective essays that they enjoyed the challenge of the course, even though it often impelled toward new ways of seeing and sometimes forced them to rethink the logical and ethical bases of the positions they held. A few students expressed the idea that they enjoyed the focus of the course and learned a great deal from reading the articles that comprised the content of the course, even if they did not attain outstanding grades.

\section{Conclusion}

In concluding, we return to the central goals of critical literacy, which invite students to think not only within the boundaries of text, but also beyond the text, to develop an awareness of the need to problematize essentialist views on complex issues, and to raise questions and seek alternative explanations in acknowledgement of the complexities of our social situations. Ultimately, this focus provides the critical vocabulary and competency that enable students to contribute in more meaningful way to conversations around such weighty issues as cultural hegemony, economic disparity, social justice, and ethical humanity. Within the University of The Bahamas classroom, rigorous intellectual engagement with issues that matter in the lives of Bahamian citizenry serves to sharpen students' critical consciousness and move them toward meaningful and sustained participation in national discourse.

\section{References}

Alexander, M. J. (2013). Not just (any) body can be a citizen: The politics of law, sexuality and postcoloniality in Trinidad and Tobago and The Bahamas. In Y. Hume \& A. Kamugisha, Caribbean Cultural Thought (pp. 91-105). Kingston, Jamaica: Ian Randle.

Anderson, G., \& Irvine, P. (1993). Informing critical literacy with ethnography. In C. Lankshear \& P. McLaren (Eds.) Critical literacy, politics, praxis, and the postmodern (pp. 81-104). Albany: SUNY Press.

Bain, M.V. (2005). Language education and Bahamian students' compositions. College of The Bahamas Research
Journal, 13, 4-23.

https://doi.org/10.15362/ijbs.v13i0.57

Bethel, N. (2007). Roots or routes: Migrations of identity in The Bahamas. Yinna: Journal of The Bahamas Association for Cultural Studies, 2, 74 93.

Brand, D. (1998). No language is neutral. Toronto: McClelland \& Stewart.

Craton, M. (1962). A history of the Bahamas. London: Collins.

Craton, M., \& Saunders, G. (1992, 1998). Islanders in the stream: A history of the Bahamian people, vol. 1 \& 11. Athens: University of Georgia Press.

Freire, P. (2009). Pedagogy of the oppressed. New York: Continuum. 
Glinton-Meicholas, P. (2000). Uncovering the Bahamian self. Yinna: Journal of The Bahamas Association for Cultural Studies, 1, 104-110.

Johnson, H. (2000). National identity and Bahamian culture. Yinna: Journal of The Bahamas Association for Cultural Studies, 1, 13-20.

Klonaris, H. (2008). Independence Day letter (2004). In T. Glave, (Ed.), Our Caribbean: A gathering of lesbian and gay writing from the Antilles (pp. 197200). Durham, NC: Duke University Press.

Oenbring, R. A., Jaquette, B., Kozikowski, C., \& Higgins, I. (2016). First year
English at the College of The Bahamas: Student perceptions. International Journal of Bahamian Studies, 22, 43-53. https://doi.org/10.15362/ijbs.v22i0.265

University of The Bahamas. (2017a). University of The Bahamas Act. Retrieved from http://www.ub.edu.bs/about-us/board-oftrustees/university-of-the-bahamas-act2016/

University of The Bahamas. (2017b). Vision, objects and mission. Retrieved from http://www.ub.edu.bs/about-us/visionmission/ 
(c) M. Sairsingh, 2017. Journal compilation (c) International Journal of Bahamian Studies, 2017 